\author{
Michele Feleppa \\ Walter Di Iorio \\ Donato M.T. Saracino
}

\section{P300 and contingent negative variation in migraine}

M. Feleppa $(\bowtie) \cdot$ W. Di Iorio Department of Neuroscience, Hospital "G. Rummo",

Via dell'Angelo, I-82100 Benevento, Italy e-mail: michele.feleppa@ao-rummo.it

Tel.: +39-0824-57492/57465

Fax: +39-0824-57465

D.M.T. Saracino

Department of Medical Up-Grading, Hospital "G. Rummo", Benevento, Italy

\begin{abstract}
We reviewed P300 and contingent negative variation (CNV) studies performed in migraine in order to identify their relevance in migraine and the role of neurophysiology in migraine. Publications available to us were completed by a Medline search. There is experimental and clinical evidence for loss of cognitive habituation in migraine which may serve as a specific diagnostic tool; therefore, we reviewed studies on migraine that analyzed habituation and lack of habituation by P300 and $\mathrm{CNV}$, performing short-term habitu-
\end{abstract}

ation (STH) and long-term habituation (LTH). Finally, we described the two components of P300 (a and b) and of CNV (early and late wave) and the two abnormalities reported from the majority of studies on event-related potential in migraine: increased amplitude of average event-related potential and lack of habituation. These abnormalities are especially related to the early component characterizing orienting activity.

Key words Migraine • P300 • CNV • Habituation
The event-related potential (ERP) component P300 is considered a cognitive neuroelectrical indicator of central nervous system activity [1] involved with the processing of new information when attention is engaged to update memory representations [2]. P300 latency can be regarded as a measure of the relative timing of the stimulus evaluation process, indicating an upper limit on categorization and stimulus evaluation time [3], or the time taken to allocate resources and engage memory updating [4]. P300 amplitude is held to index attentional resource allocation when memory updating is engaged [2]. The P300 component in many event-related brain potential (ERP) studies is obtained using the so-called odd-ball paradigm, in which two stimuli are presented in random order, with one occurring more frequently than the other [5]. The subject is required to discriminate the infrequent or rare stimulus ("target stimulus") from the frequent or standard stimulus ("nontarget") by noting the occurrence of the target - typically by pressing a button or mental counting [6, 7]. A modification of the oddball paradigm has been developed in which infrequent-nontarget stimuli are inserted into the sequence of target and standard stimuli. When "novel" stimuli (e.g., dog barks, color forms, etc.) are presented as the infrequent nontargets in the series of more "typical" targets and standard stimuli (e.g., tones, letters of the alphabet, etc.), a P300 component that is large over the frontal/central areas is produced. This component has been dubbed the "P3a," whereas the infrequent-target stimulus elicits a parietal maximum $\mathrm{P} 300$ or "P3b" $[8,9]$. Because this novel P300 exhibits an anterior/central scalp distribution, short peak latency, and rapid habituation, it has been interpreted as reflecting frontal lobe function 
$[10,11]$. In the 1960s, electrophysiologists described a slow negative wave, called the contingent negative variation $(\mathrm{CNV})$, that can be recorded on the brain cortical surface between two defined and contingent external stimuli [12]. The first stimulus serves as a warning (S1); it announces an imperative stimulus (S2) which can be directly acted upon by pressing a key. When the interval between $\mathrm{S} 1$ and S2 is longer than 2 s, two CNV components can be distinguished: (1) an "early component," which has its greatest amplitude between 550 and $750 \mathrm{~ms}$ after S1, and (2) a "late component," which shows a maximum amplitude in the $200 \mathrm{~ms}$ preceding S2. The negativity is not seen in the raw EEG and can only be detected with averaging [13]. The CNV amplitude is associated with expectation, attention, preparation, motivation, and readiness [12, 14, 15]. The expectation of stimuli can selectively reduce brain activation [16], while the anticipatory state itself may be associated with increased blood flow in the anterior cingulated cortex [17]. The early component is observed predominantly frontally and related to the attention to stimulus; the late component has a more central distribution and is associated with motor readiness [18]. The late CNV may consist of motor preparation and stimulus preceding negativity, or SPN [19]. There is evidence for multiple sources of CNV [20]. The anterior cingulated gyrus, caudate nucleus, thalamus, and reticular formation may be critical for the generation of the early phase of $\mathrm{CNV}$, and the dorsolateral prefrontal cortex may be involved in the generation of the late phase [21]. The early CNV may also originate in the frontal lobes [22]. The frontal cortex is known to be a crucial structure for working memory, as confirmed in functional magnetic resonance imaging, positron emission tomography (PET) imaging, and direct neuronal recordings, and it may be functionally specialized [23]. Loveless and Sanford [24] called the two components of the CNV "O-wave" (or orienting wave following the warning signal) and "E-wave" (or expectancy wave anticipating the imperative signal) in order to denote their hypothesized functional significance. According to Rohrbaugh et al. [25], the early CNV observed in S1-S2 paradigms with long interstimulus intervals ( $3 \mathrm{~s}$ or more) is identical to the negative afterwave or slow negative wave (SNW) elicited by unpaired stimuli. Both early $\mathrm{CNV}$ and SNW are sensitive to task requirements enhancing the signal value of the stimuli [26]. For example, very much in the way the early CNV responds to the signal value of the warning stimulus, the amplitude of the SNW increases when a simple counting task is imposed or discrimination of various stimuli is required [27]. The increase seems to depend on the difficulty of the task [28]. The extent, however, to which these waves may be held to be a manifestation of orienting activity is, according to Rohrbaugh and Gaillard [29], "an important but largely unexplored problem". At least two O-wave components were described [24, 27, 28]. The first component peaking at about $500 \mathrm{~ms}$ or a little later is followed by a second broadly distributed wave. While the first is negative at frontal scalp sites (slow negative wave 1, SNW1) and usually positive parietally (slow positive wave, SPW), the later component of the O-wave (SNW2) is uniformly negative at all sites, but tends to be strong predominantly at frontal or central sites. Results of more recent investigations suggest that the anterior negative and the posterior positive aspects of the $\mathrm{O}$-wave are independent and can be dissociated [10, 24]. Support for assumptions relating the $\mathrm{O}$-wave to orienting activity comes from different lines of evidence. First, it is suggested by the bilateral distribution of the O-wave. Particularly the late, SNW2, component appears to be more pronounced over the right hemisphere [27]. This laterality agrees with hypotheses linking orienting and attention with functions of the right hemisphere [30]. Furthermore, the anterior-posterior gradient of the $\mathrm{O}$ wave is in accordance with neuropsychological and neurophysiological literature relating the frontal cortex to attentional processes incorporated in orienting [31]. Also, the effects of different experimental manipulations on elicitation and magnitude of the $\mathrm{O}$-wave seem to confirm its relationship to orienting and attention [27]. The amplitude of the O-wave, for example, appears to depend on manipulations affecting task relevance and stimulus significance [24, 27, 29].

In healthy subjects, the amplitude of evoked cortical responses normally decreases with repetitive presentation of a stimulus. This phenomenon is commonly referred to as habituation [32], and one of its metabolic advantages could be protection against overexcitation and lactate accumulation in sensory cortices [33].

Migraine patients, unlike healthy control subjects, show a dissimilar electrophysiological behavior, as shown for visual-evoked potentials (VEPs), which fail to habituate to repeated stimuli and sometimes even potentiate [34, 35]. This also holds true for ERPs [36]. It has been hypothesized that the simultaneous occurrence of this deficit of habituation and a reduced mitochondrial energy reserve might lead to the activation of the trigeminovascular system, culminating in the migraine attack [37]. Extensive research on EP habituation described two main kinds of physiological phenomena: short-term habituation (STH) and long-term habituation (LTH) [38]. The STH occurs when individual stimuli are repeated at short interstimulus intervals and is often attributed to a refractory period [39] or sensory gating [40]. It has been proposed that, if the stimuli are presented in pairs, the first stimulus activates excitatory inputs that cause a neuronal response as well as inhibitory pathways that induce a suppression 
of neuronal activity on the following stimulus. These processes result in STH [41]. This form of habituation is independent of stimulus intensity, psychological characteristics of the stimulus, and attentional demands, and is possibly under strong genetic control [40-42]. In particular, the STH of the P50 (P1), a positive peak occurring about 40-90 ms after stimulus onset, has been intensively investigated because of its relevance in a number of psychiatric and neurological disorders [40, 42, 43]. The LTH occurs across blocks of stimuli lasting minutes and is often explained with the "dual-process" theory of Thompson and Spencer [32] or the "comparator" theory of Sokolov [44]. It has been suggested that the habituation of a neuronal response occurs when the external events of the environment and the internal neural model are matched and no longer produce an orienting response of attentional focus [32, 39, 44, 45]. This habituation depends on the intensity, psychological significance of the stimulus, and attentional resources [38, 39, 45, 46]. The LTH was investigated most often for the P300 wave in the "odd-ball" paradigm and requires allocation of attentional resources $[43,47]$. In summary, the STH is more probably related to the preattentive screening out of irrelevant stimuli [39-41], while the LTH is attributed to the attentive processes of the orienting response [32, 43, 44, 47].

Migraine patients are also distinguished by a higher dependence of their auditory-evoked cortical responses on stimulus intensity than healthy volunteers [48, 49]. This increased intensity dependence of auditory potentials (IDAP) is, like sensitization, only detectable interictally [50]. The middle latency auditory potentials are complex neuronal phenomena that depend on thalamo-cortico-thalamic activities and various state-setting subcortico-cortical pathways; there is, nonetheless, indirect evidence that IDAP is inversely correlated with central serotonergic transmission [51]. If deficient, the latter may lead to a decreased cortical preactivation level and possibly be the basis for the observed lack of habituation in migraineurs [52].

It has been hypothesized hat the strong IDAP found in migraineurs might be due to a deficit of habituation to high-intensity stimuli [53], and thus these two distinct phenomena may in fact be expressions of the same dysfunction in habituation. Migraine patients are characterized as having attacks caused by a deficit of habituation, or even potentiation, of cortical-evoked and ERPs. Another interictal electrophysiological abnormality found in migraineurs is a marked dependence on the intensity of auditory-evoked cortical potentials. In contrast to habituation which is measured during repetition of a stimulus at the same intensity, IDAP is obtained after stimulations of increasing intensities. These two electrophysiological phenomena are thought to reflect different aspects of cortical information processing, and their impairment in migraine may be directly or indirectly related to decreased activity in the state-setting monoaminergic projections to the sensory cortices [54]. Habituation, i.e., amplitude reduction of a cortical response to a sustained stimulus of equal intensity, is considered to reflect an adaptive cortical mechanism protecting from sensory overstimulation [55] and lactate accumulation [33]. In the Aplysia gillwithdrawal reflex, habituation is controlled by serotonergic neurons [56]. Although habituation of long latency cortical-evoked responses in the human brain is likely to have more complex underlying molecular mechanisms, there are some arguments suggesting that it might be inversely related to serotonin activity. Evers et al. [57] have shown in migraineurs that habituation, assessed by a latency increase of the event-related visual P300 response, varies inversely with platelet serotonin content; in particular, it arguments, i.e., normalizes, during the attack in parallel with a decrease in platelet serotonin. Normalization of amplitude habituation during the attack was also found for VEPs [58] and CNV [59]. In a recent study, Siniatchkin et al. [43] demonstrate that migraine patients are characterized by two kinds of habituation deficits compared with healthy subjects: (a) the sensory gating deficit or reduced STH of the P50 wave, independent of attentional demands to the stimulation, and (b) the LTH of the P300 wave under circumstances of increased cortical processing and enhanced mobilization of attentional resources. These habituation deficits represent abnormalities of different levels of information processing in migraine. The reduced P50 STH possibly represents the impairment of an early stage of the automatic screening out of stimuli, whereas the P300 LTH deficit results from disturbed cognitive processing. According to the authors, how the STH and LTH are related, and which mechanisms underlie these abnormalities, needs to be investigated in further studies.

The majority of studies on evoked and event-related potentials in migraine have shown two abnormalities: increased amplitudes of averages of large numbers of trials and lack of habituation in successive trial blocks [60]. At first sight, increased amplitudes of cortical-evoked responses would favor the hypothesis of cortical hyperexcitability in migraine between attacks [61]. However, it is useful to remember that evoked responses are averaged over a large number of stimulations and that for low numbers of trials amplitudes were lower, not higher, than in healthy volunteers [60]. The suggestion has been made therefore that the increase of EP amplitude found in some studies was not due to cortical hyperexcitability, but merely to the lack of habituation of the responses during sustained stimulation [34]. In the strict physiological sense, hyperexcitability indeed indicates that the threshold to obtain a response is decreased and/or that a greater 
response is induced by a given suprathreshold stimulus [54]. Although habituation is a complex neurobiological phenomenon, it might uniquely depend, for corticalevoked activation, on the preactivation excitability level. According to the "ceiling theory" [62], which is most often applied to explain the occurrence of an "augmenting" or "reducing" response to increasing stimulation intensities, a low preactivation level of sensory cortices allows a wider range of suprathreshold activation before reaching the ceiling and initiating a reducing response, i.e., habituation. This theory, applied to EP findings in migraineurs, would explain both the low first-block amplitude for most EPs and the lack of habituation on trial repetition [54]. There is evidence that the preactivation level of cortical excitability depends on the so-called state-setting, chemically addressed connections that originate in the brain stem and involve serotonin and noradrenaline as transmitters $[63,64]$. Low interictal activity of these systems, especially of the raphe-cortical serotoninergic pathway, could indeed be responsible for the observed electrophysiological abnormalities in migraineurs [65]. If this hypothesis is correct, one would expect that decreasing cortical activation would produce lack of habituation in healthy volunteers, and vice versa, that increasing activation in migraineurs would normalize their habituation patterns [54]. This was indeed recently demonstrated by using repetitive transcranial magnetic stimulation (rTMS). High-frequency rTMS of the occipital cortex, known to activate the underlying cortex, was followed by a normalization of VEP habituation in migraineurs, while low-frequency rTMS, which has an inhibitory effect, induced a VEP habituation deficit in normal control subjects [66]. The precise relationship between interictal abnormal cortical information processing and migraine pathogenesis remains to be determined. The possibility that dysfunctional monoaminergic nuclei in the brain stem may play a causative role in migraine attacks [67], and may be responsible independently for interictal lack of habituation of evoked potentials as an epiphenomenon, cannot be excluded. We know that cortical habituation is also a protective mechanism against overstimulation [33] and that the mitochondrial phosphorylation potential as studied by magnetic resonance spectroscopy is reduced interictally in the brain of migraineurs [68-70]. Lack of habituation may favor, under certain circumstances, a metabolic disequilibrium, which would lead to activation of the major pain-signaling system of the brain, the trigeminovascular system [71]. The ictal normalization of EP amplitudes and habituation suggests that there is, in close temporal proximity to the migraine attack, an increase in the cortical preactivation level, probably due to enhanced activity in raphe-cortical serotoninergic pathways [54]. Interestingly, the ictal normal- ization of visual-evoked $\mathrm{P} 3$ habituation is accompanied by a decrease in platelet serotonin content [57], and two PET studies have shown brain stem activation during the migraine attack $[67,72]$. According to the biobehavioral theory of migraine [73], this ictal normalization of electrophysiological findings could be part of a homeostatic process. Various studies have demonstrated a more negative bCNV in patients with migraine during foreperiods that are shorter than 2 s [74]. Studies employing longer foreperiods predominantly report a higher early wave amplitude in migraine without aura [75-77], but higher late wave amplitudes have also been reported [75]. The higher CNV amplitudes are believed to emerge as a result of the slow habituations over trials [74, 76, 78]. Research in cortical electrophysiology such as that embracing the thalamic gating model [77] or the threshold regulation theory [79] has linked the CNV to cortical negative brain potentials, such as the $\mathrm{CNV}$, reflecting the task-related tuning of cortical areas. The threshold regulation theory postulates that preparation is achieved by lowering neuronal firing thresholds in the appropriate cortical neuronal networks and by selectively increasing cortical excitability. This is ultimately reflected in an enhanced negativity in these particular cortical areas. In agreement with these ideas, migraine researchers have generally attributed these CNV findings to a hyperactivity of central catecholaminergic systems [80, 81]. High catecholaminergic activity is thought to induce a state of cortical hyperexcitability and arousal that presents normal habituation [82]. The early wave increases even more during the days before an attack but decreases to the level of healthy control subjects during the attack [82]. Along with this normalization of CNV early wave amplitude, the impaired habituation also resolves during the attack [77]. In the 2-3 days following the attack, the CNV remains at this normal level after which it gradually deteriorates again [83]. This normalization during an attack has been suggested to be related to the depletion of noradrenaline activity combined with an increased serotoninergic transmission [84]. During the postattack period, Mulder et al. [82] demonstrated lower CNV early and late wave amplitudes over the frontal cortex in migraineurs without aura compared with control subjects, suggesting postattack hypoexcitability of the frontal cortex. Concordant studies from different laboratories have shown that $\mathrm{CNV}$ amplitude is increased in migraineurs between attacks, mainly in those suffering from migraine without aura $[75,76,78,85,86]$. This increase was more pronounced for the early component in comparison with healthy volunteers or tension-type headache patients [76], which can be interpreted as disturbed attention and possibly reflect an excess of excitatory versus inhibitory processes. When taking into account age as a variable [87], decrease in early CNV amplitude 
with aging was found in healthy volunteers but not in migraineurs, which the authors interpreted as a disturbance of cerebral maturation. Disease duration also had an effect on CNV abnormalities in migraineurs [88]. A strong familial influence on CNV parameters was reported by Siniatchkin et al. [89], who found abnormalities not only in migraineurs but also in healthy subjects with a positive family history for migraine [90]. The sensitivity of CNV to different prophylactic agents used in migraine and the relative specificity of the difference between headache forms suggest that $\mathrm{CNV}$ is a useful method for studying headaches [91]. Siniatchkin et al. [92] found differences in habituation of the early component of CNV in migraine and chronic daily headache $(\mathrm{CDH})$; however, in the latter, these differences have been related to lower baseline amplitudes, and the authors conclude that CNV may be considered a predictive variable for transformed migraine. According to Aurora [93], depression may also have played a role in the $\mathrm{CNV}$ difference in $\mathrm{CDH}$, and also comorbidity (i.e., depression and analgesic overuse) may alter CNV.

Studies of the P300 component of the classic "odd-ball" paradigm of ERPs in migraine gave conflicting results. A reduced P300 amplitude and a prolonged latency were found when an auditory stimulus was used [94, 95], except in one study [96]. In a paradigm with visual stimuli, however, there were no differences in P300 amplitude, but prolonged P300 latency in migraine without aura [36, 57, 97]. In the passive odd-ball paradigm, latency and amplitude of the $\mathrm{P} 3 \mathrm{a}$ component, which reflects automatic processing of a "novel" stimulus, were on average normal interictally in migraine [98].

\section{References}

1. Regan D (1989) Human brain electrophysiology. Evoked potentials and evoked magnetic fields in science and medicine. Elsevier, New York

2. Polich J (1996) Meta-analysis of P300 normative aging studies. Psychophysiology 33:334-353

3. Coles MGH, Smid HGOM, Scheffers MK, Otten LJ (1995) Mental chronometry and the study of human information processing. In: Rugg MD, Coles MGH (eds) Electrophysiology of mind. Oxford University Press, New York, pp 86-131

4. Fjell AM, Walhovd KB (2001) P300 and Neuropsychological tests as measures of aging: scalp topography and cognitive changes. Brain Topogr 14:25-40

5. Demiralp T, Ademoglu A, Comerchero M, Polich J (2001) Wavelet analysis of P3a and P3b. Brain Topogr 13:252-67

6. Picton TW (1992) The P300 wave of the human event-related potential. J Clin Neurophysiol 9:456-479

7. Polich J (1999) P300 in clinical applications: meaning, methods and measurements. In: Niedermeyer E, Lopes da Silva FH (eds)

Electroencephalography: basic principles, clinical applications, and related fields. William \& Wilkins, Baltimore, pp 1079-1091
8. Courchesne E, Hillyard SA, Galambos R (1975) Stimulus novelty, task relevance and the visual evoked potential in man. Electroencephalogr Clin Neurophysiol 39:131-143

9. Squires N, Squires K, Hillyard S (1975) Two varieties of long-latency positive waves evoked by unpredictable auditory stimuli in man. Electroencephalogr Clin Neurophysiol 38:387-401

10. Friedman D, Simpson GV (1994) ERP amplitude and scalp distribution to target and novel events: effects of temporal order in young, middle-aged and older adults. Cog Brain Res 2:49-63

11. Knight R (1996) Contribution of human hippocampal region to novelty detection. Nature 383:256-259

12. Walter WG, Cooper R, Aldrige VJ, McCallum WC, Winter AL (1964) Contingent negative variation: an electric sign of sensory-motor association and expectancy in the human brain. Nature 203:380-384

13. Kropp P, Gerber WD (1995) Contingent negative variation during migraine attack and interval: evidence for normalization of slow cortical potentials during the attack. Cephalalgia 15:123-128
14. Rizzo PA, Amabile G, Caporali M, Spadaro M, Zanasi M, Morocuti CA (1978) CNV study in a group of patients with traumatic head injuries. Electroencephalogr Clin Neurophysiol 45:281

15. Rockstroh B, Elbert T, Birbaumer N, Lutzenberger W (1982) Slow brain potentials and behavior. Urban \& Schwarzenberg, Munich

16. Drevets WC, Burton H, Videen TO, Snyder AZ, Simpson JR, Raichle ME (1995) Blood flow changes in human somatosensory cortex during anticipated stimulation. Nature 373:249-252

17. Murtha S, Chertkow H, Beauregard M, Dixon R, Evans A (1996) Anticipation caused increased blood flow to the anterior cingulated cortex. Hum Brain Mapp 4:103-112

18. Mnatsakanian EV, Tarkka IM (2002) Task-specific expectation is revealed in scalp recorded slow potentials. Brain Topogr 15:87-94

19. Brunia CH (1988) Movement and stimulus preceding negativity. Biol Psychol 26:165-178

20. Hamano T, Luder HO, Ikeda A, Coldura TF, Comair YG, Shibasaki H (1997) The cortical generators of the contingent negative variations in humans: a study with subdural electrodes. Electroencephalogr Clin Neurophysiol 104:257-268 
21. Rosahl SK, Knight RT (1995) Role of prefrontal cortex in generation of the CNV. Cereb Cortex 2:123-124

22. Cui RQ, Egkher A, Huter D, Lang W, Lindinger G, Deecke L (2000) High resolution spatiotemporal analysis of the contingent negative variation in simple or complex motor tasks and a non motor task. Clin Neurophysiol 111:1847-1859

23. Fletcher PC, Henson RNA (2001) Frontal lobes and human memory. Insights from functional neuroimaging. Brain 124:849-881

24. Loveless NE, Sanford AJ (1974) Effects of age on the contingent negative variation and preparatory set in a reaction-time task. J Gerontol 29:52-63

25. Rohrbaugh JW, Syndulko K, Lindsley DB (1976) Brain wave components of the contingent negative variation in humans. Science 191:1055-1057

26. Zimmer H, Demmel R (2000) Habituation and laterality of orienting processes as reflected by slow negative waves. Biol Psych 53:161-76

27. Rohrbaugh JW (1984) The orienting reflex: performance and central nervous system manifestations. In: Parasuraman R, Davies R (eds) Varieties of attention. Academic Press, Orlando, Fl, pp 323-373

28. Rohrbaugh JW, Syndulko K, Lindsley DB (1978) Cortical slow negative waves following non-paired stimuli: effects of task factors.

Electroencephalogr Clin Neurophysiol 45:551-567

29. Rorbaugh JW, Gaillard AWK (1983) Sensory and motor aspects of the contingent negative variation. In: Gaillard AWK, Ritter W (eds) Tutorials in Event related potential research: endogenous components. NorthHolland Publishing, Amsterdam, pp 269-310

30. Heilman KM, Van den Abell T (1980) Right hemisphere dominance for attention: the mechanism underlying hemispheric asymmetrics of inattention (neglect). Neurology 30:327-330

31. Giard M-H, Perrin F, Pernier J, Bouchet $P$ (1990) Brain generators implicated in the processing of auditory stimulus deviance: a topographic event related potential study. Psychophysiol 27:627-640
32. Thompson R, Spencer WA (1966) Habituation. A model phenomenon for the study of neuronal substrates of behaviour. Psychol Rev 22:16-43

33. Sappey-Marinier D, Galabrese G, Fein G, Hugg JW, Biggins C, Weiner MW (1992) Effect of photic stimulation on human visual cortex lactate and phosphates using $1 \mathrm{H}$ and $31 \mathrm{P}$ magnetic resonance spectroscopy. J Cereb Blood F Met 22:584-592

34. Schoenen J, Wang W, Albert A, Delwaide PJ (1995) Potentiation instead of habituation characterizes visual evoked potentials in migraine patients between attacks. Eur J Neurol 22:115-122

35. Afra J, Cecchini AP, De Pasqua V, Albert A, Schoenen J (1998) Visual evoked potentials during long periods of pattern-reversal stimulation in migraine. Brain 121:233-241

36. Evers S, Bauer B, Suhr B, Husstedt IW, Grotemeyer KH (1997) Cognitive processing in primary headache: a study on event-related potentials. Neurology 48:108-113

37. Schoenen J (1996) Deficient habituation of evoked cortical potentials in migraine: a link between brain biology, behavior and trigeminovascular activation. Biomed Pharmacother 22:71-78

38. Woods DL, Elmasian R (1986) The habituation of event-related potentials to speech sounds and tones. Electroencephal Clin Neurophysiol 65:447-459

39. Roemer RA, Shagass C, Teyler TJ (1984) Do human evoked potentials habituate? In: Peeke HV, Petrinovich L (eds) Habituation, sensitization, and behaviour. Academic Press, New York, pp 325-346

40. Adler LE, Freedman R, Ross RG, Olincy A, Waldo MC (1999)

Elementary phenotypes in the neurobiological and genetic study of schizophrenia. Biol Psych 46:8-18

41. Freedman R, Waldo M, BickfordWimer P, Nagamoto H (1991) Elementary neuronal dysfunction in schizophrenia. Schizophr Res 4:233-243

42. Schwarzkopf SB, Lamberti S, Smith DA (1993) Concurrent assessment of acoustic startle and auditory P50 evoked potential measures of sensory inhibition. Biol Psych 33:815-28
43. Siniatchkin M, Kropp P, Gerber W-D (2003) What kind of habituation is impaired in migraine patients? Cephalalgia 23:511-518

44. Sokolov E (1963) Perception and the conditioned reflex. Pergamon, Oxford

45. Loveless N (1983) The orienting response and evoked potentials in man. In: Siddle D (ed) Orienting and habituation: perspectives in human research. John Wiley, New York, pp 71-108

46. Woods DL, Elmasian R (1986) The habituation of event-related potentials to speech sounds and tones.

Electroencephal Clin Neurophysiol 65:447-459

47. Polich J, McIsaac HK (1994) Comparison of auditory P300 habituation from active and passive conditions. Int J Psychophysiol 17:25-34

48. Wang W, Timsit-Berthier M, Schoenen J (1996) Intensity dependence of auditory evoked potentials is pronounced in migraine: an indication of cortical potentiation and low serotoninergic neurotransmission. Neurology 22:1404-1409

49. Siniatchkin M, Kropp P, Neumann M, Gerber W, Stephani U (2000) Intensity dependence of auditory evoked cortical potentials in migraine families. Pain 22:247-54

50. Áfra J, Sandor PS, Schoenen J (2000) Habituation of visual and intensity dependence of auditory evoked cortical potentials tends to normalize just before and during the migraine attack. Cephalalgia 22:714-719

51. Hegerl U, Juckel G (1993) Intensity dependence of auditory evoked potentials as an indicator of central serotoninergic neurotransmission: a new hypothesis. Biol Psychiatry 22:173-187

52. Schoenen J (1996) Deficient habituation of evoked cortical potentials in migraine: a link between brain biology, behavior and trigeminovascular activation. Biomed Pharmacother 22:71-78

53. Wang W, Timsit-Berthier M, Schoenen J (1996) Intensity dependence of auditory evoked potentials is pronounced in migraine: an indication of cortical potentiation and low serotonergic neurotransmission. Neurology 22:1404-1409 
54. Ambrosini A, Rossi P, De Pasqua V, Pierelli F, Schoenen J (2003) Lack of habituation causes high intensity dependence of auditory evoked cortical potentials in migraine. Brain 126:2009-2015

55. Thompson RF, Berry SD, Rinaldi PC, Berger TW (1979) Habituation and orienting reflex: the dual-process theory revised. In: Kimmel HD, van Olst EH, Orlebeke JF (eds) The orienting reflex in humans. Lawrence Erlbaum, Hillsdale, NJ, pp 21-60

56. Kandel ER (1991) Cellular mechanisms of learning and biological basis of individuality. In: Kandel ER, Schwartz JH, Jessell TM (eds) Principles of neural science, 3rd edn. Elsevier, New York, pp 1009-1031

57. Evers S, Quibeldey F, Grotemeyer KH, Suhr B, Husstedt IW (1999) Dynamic changes of cognitive habituation and serotonin metabolism during the migraine interval. Cephalalgia 19:485-91

58. Judit A, Sándor P, Schoenen J (2000) Habituation of visual and intensity dependence of auditory evoked cortical potentials tends to normalize just before and during the migraine attack. Echolalia 20:714-719

59. Kropp P, Gerber WD (1995) Contingent negative variation during migraine attack and interval: evidence for normalization of slow cortical potentials during the attack. Cephalalgia 15:123-8

60. Ambrosini A, de Noordhout A, Sàndor PS, Schoenen J (2003)

Electrophysiological studies in migraine: a comprehensive review of their interest and limitations. Cephalalgia 23:13-31

61. Welch KMA, D'Andrea G, Tepley N, Barkley G, Ramadan NM (1990) The concept of migraine as a state of central neuronal hyperexcitability. Neurol Clin 8:817-828

62. Knott JR, Irwin DA (1973) Anxiety, stress and the contingent negative variation. Arch Gen Psychiatry 29:538-541

63. Hegerl U, Juckel G (1993) Intensity dependence of auditory evoked potentials as an indicator of central serotonergic neurotransmission: a new hypothesis. Biol Psychiatry 33:173-187
64. Mesulam MM (1990) Large-scale neurocognitive networks and distributed processing for attention, language and memory. Ann Neurol 28:597-613

65. Schoenen J (1996) Abnormal cortical information processing between migraine attacks. In: Sandler M, Ferrari M, Harnett S (eds) Migraine pharmacology and genetics. Altman, London, pp 233-253

66. Bohotin V, Fumal A, Vandenheede M, Gérard P, Bohotin C, Maertens de Noordhout A et al (2002) Effects of repetitive transcranial magnetic stimulation on visual evoked potentials in migraine. Brain 125:1-11

67. Weiller C, May A, Limmroth V, Juptner M, Kaube H, Schayck RV et al (1995) Brain stem activation in spontaneous migraine attacks. Nature Med 1:658-660

68. Welch KMA, Levine SR, D'Andrea G, Schultz L, Helpern JA (1989) Preliminary observations on brain energy metabolism in migraine studied by in vivo 31-phosphorus NMR spectroscopy. Neurology 39:538-541

69. Barbiroli B, Montagna P, Cortelli P, Funicello R, Iotti S et al (1992) Abnormal brain and muscle energy metabolism shown by 31P magnetic resonance spectroscopy in patients affected by migraine with aura. Neurology 42:1209-1214

70. Montagna P, Cortelli P, Monari L, Pierangeli G, Parchi P et al (1994) 31P-Magnetic resonance spectroscopy in migraine without aura. Neurology 44:666-668

71. Schoenen J (1994) Pathogenesis of migraine: the biobehavioural and hypoxia theories reconciled. Acta Neurol Belg 94:79-86

72. Sándor PS, Dydak U, Schoenen J, Crelier G, Kollias S et al (2000) Functional magnetic resonance spectroscopic imaging (fMRSI) shows cortical lactate changes during prolonged visual stimulation in migraine with aura: the metabolic equivalent of electrophysiological dyshabituation? Cephalalgia 20:277

73. Welch KMA (1986) Migraine: a biobehavioural disorder. Cephalalgia [Suppl. 4]:103-110

74. Schoenen J, Maertens de Noordhout A, Timsit-Berthier M, Timsit M (1986) Contingent negative variation and efficacy of beta-blocking agents in migraine. Cephalalgia 6:229-233
75. Böcker KB, Timsit-Berthier M, Schoenen J, Brunia CH (1990) Contingent negative variation in migraine. Headache 30:604-609

76. Kropp P, Gerber WD (1993) Is increased amplitude of contingent negative variation in migraine due to cortical hyperactivity or to reduced habituation? Cephalalgia 13:37-41

77. Kropp P, Gerber WD (1995) Contingent negative variation during migraine attack and interval: evidence for normalization of slow cortical potentials during the attack. Cephalalgia 15:123-128

78. Maertens de Noordhout A, TimsitBerthier M, Timsit M, Schoenen J (1986) Contingent negative variation in headache. Ann Neurol 19:78-80

79. Rockstroh B, Elbert T, Canavan A, LutzenbergerW, Birbaumer N (1989) Slow cortical potentials and behavior. Urban \& Schwarzenberg, Baltimore

80. Timsit-Berthier M, Mantanus H, Poncelet M, Marissiaux P, Legros JJ (1986) Contingent negative variation as a new method to assess the catecholaminergic systems. In: Gallai V (ed) Maturation of the CNS and evoked potentials. Elsevier, New York, pp 260-268

81. Nagel-Leiby S, Welch KM, D'andrea G, Grunfeld S, Brown E (1990) Eventrelated slow potentials and associated catecholamine function in migraine. Cephalalgia 10:317-329

82. Mulder EJCM, Linssen WHJP, Passchier J, de Geus EJC (2001) Interictal and postictal contingent negative variation in migraine without aura. Headache 41:72-78

83. Kropp P, Gerber WD (1998) Prediction of migraine attacks using a slow cortical potential, the contingent negative variation. Neurosci Lett 257:73-76

84. Gerber WD, Schoenen J (1998) Biobehavioral correlates in migraine: the role of hypersensitivity and information-processing dysfunction. Cephalalgia 18[Suppl 21]:5-11

85. Schoenen J, Maertens A, TimsitBerthier, Timsit M (1985) Contingent negative variation $(\mathrm{CNV})$ as a diagnostic and physiopathologic tool in headache patients. In: Rose FC (ed) Migraine. Clinical and research advances. Karger, Basel, pp 17-25 
86. Schoenen J, Timsit-Berthier M, Timsit M (1985) Correlations between contingent negative variation and plasma levels of catecholamines in headache patients. Cephalalgia 5 [Suppl 1]:480

87. Kropp P, Kirbach U, Detlefsen JO, Siniatchkin M, Gerber WD, Stephani U (1999) Slow cortical potentials in migraine: a comparison of adults and children. Cephalalgia 19[Suppl 25]:60-64

88. Kropp P, Siniatchkin M, Gerber WD (2000) Contingent negative variation as indicator of duration of migraine disease. Funct Neurol 15[Suppl 3]:78-81

89. Siniatchkin M, Kirsch E, Kropp P, Stephani U, Gerber WD (2000) Slow cortical potentials in migraine families. Cephalalgia 20:881-892
90. Siniatchkin M, Kropp P, Gerber WD (2001) Contingent negative variation in subjects at risk for migraine without aura. Pain 94:159-167

91. Maertens de Noordhout A, TimsitBerthier M, Timsit M, Schoenen J (1987) Effects of beta blockade on contingent negative variation in migraine. Ann Neurol 21:11-112

92. Siniatchkin M, Gerber W-D, Kropp P, Vein A (1998) Contingent negative variation in patients with chronic daily headache. Cephalalgia 18:565-569

93. Aurora SK (1998) CNV in CDH. Editorial commentary. Cephalalgia 18:531

94. Drake ME, Pakalnis A, Padamadan H (1989) Long-latency auditory event related potentials in migraine. Headache 29:239-241
95. Wang W, Schoenen J, Timsit-Berthier M (1995). Cognitive functions in migraine without aura between attacks: a psychophysiological approach using the 'oddball' paradigm. Neurophysiol Clin 25:3-11

96. Mazzotta G, Alberti A, Cantucci A, Gallai V (1995) The event-related potential P300 during headache-free period and spontaneous attack in adult headache sufferers. Headache 35:210-215

97. Evers S, Bauer B, Grotemeyer KH, Kurlemann G, Husstedt IW (1998) Event-related potentials (P300) in primary headache in childhood and adolescence. J Child Neurol 13:322-326

98. Wang W, Schoenen J (1998) Interictal potentiation of passive 'oddball' auditory event-related potentials in migraine. Cephalalgia 18:261-265 